\title{
Hugues Daussy, Le parti huguenot. Chronique d'une désillusion (1557-1572)
}

\section{Michele Mastroianni}

\section{Q OpenEdition}

1 Journals

\section{Edizione digitale}

URL: http://journals.openedition.org/studifrancesi/407

DOI: $10.4000 /$ studifrancesi.407

ISSN: 2421-5856

\section{Editore}

Rosenberg \& Sellier

\section{Edizione cartacea}

Data di pubblicazione: 1 aprile 2015

Paginazione: 136-137

ISSN: 0039-2944

\section{Notizia bibliografica digitale}

Michele Mastroianni, « Hugues Daussy, Le parti huquenot. Chronique d'une désillusion (1557-1572)»,

Studi Francesi [Online], 175 (LIX | I) | 2015, online dal 01 avril 2015, consultato il 18 septembre 2020. URL : http://journals.openedition.org/studifrancesi/407; DOI : https://doi.org/10.4000/studifrancesi. 407

Questo documento è stato generato automaticamente il 18 settembre 2020.

\section{(c)}

Studi Francesi è distribuita con Licenza Creative Commons Attribuzione - Non commerciale - Non opere derivate 4.0 Internazionale. 


\title{
Hugues Daussy, Le parti huguenot. Chronique d'une désillusion (1557-1572)
}

\author{
Michele Mastroianni
}

\section{NOTIZIA}

HUGUES DAUSSY, Le parti huguenot. Chronique d'une désillusion (1557-1572), Genève, Droz, 2014 («Travaux d'Humanisme et Renaissance», n. DXXVII), pp. 882.

1 Hugues Daussy, uno dei più validi storici del protestantesimo francese del secondo Cinquecento, dopo aver consacrato la sua thèse de doctorat a ricostruire il pensiero e l'impegno politico di Duplessis-Mornay (Les huguenots et le roi: le combat politique de Philippe Duplessis-Mornay, 1572-1600, Genève, Droz, 2002) - e attraverso lo studio di questo personaggio a ricostruire la politica protestante, sul piano pratico e su quello teorico, negli anni che precedono l'editto di Nantes -, ha dedicato il suo lavoro di habilitation allo studio delle scelte politiche dei réformés negli anni che precedono la Saint-Barthélemy. Sono anni che sono stati relativamente trascurati dalla storiografia, per quanto riguarda la formazione e strutturazione di un "partito" huguenot. Il periodo studiato - dal 1557 al 1572 - vede affermarsi, da parte dei protestanti, non soltanto la speranza ma la convinzione di un possibile trionfo della Riforma in Francia, convinzione che si trasformerà, con la Saint-Barthélemy, in disillusione. Per l'A., pertanto, «il a paru intéressant d'étudier non seulement l'imaginaire, dans lequel s'est enraciné ce fol espoir d'une victoire totale, mais aussi les moyens humains auxquels les leaders du mouvement réformé ont eu recours, afin de transformer leur rêve en réalité». Questi «mezzi umani» sarebbero appunto la messa in opera di una vera e propria organizzazione politica. Ora, mentre gli storici della Riforma francese si sono essenzialmente occupati della formazione e del funzionamento del sistema ecclesiastico, l'indagine di H. Daussy ricostruisce le strutture politiche - evidenziando quella che definisce l'«autonomisation de la structure politico-militaire», creata in parallelo al sistema presbitero-sinodale - e illustra i movimenti di una società parallela con i suoi centri di potere e i suoi capi, il cui enjeu è di fare cambiare rotta alla Francia 
cattolica, tentando di spostare sulle proprie posizioni la corona (la regina madre e il re). Il discorso dello storico si appoggia su una documentazione ricchissima: corrispondenze, rapporti di ambasciatori, verbali di assemblee politiche e di assemblee sinodali, una grande massa di pamphlets, la letteratura polemica (soprattutto poesia e teatro). All'analisi più propriamente storica si intreccia sempre la ricostruzione dei contenuti ideali che animano la politica, soprattutto la ricostruzione di una mitologia réformée (di quella, per esempio, che viene definita la rhétorique du peuple élu). Per questo il volume, che segnerà una pietra miliare nella storia della Riforma francese, risulta un testo utile anche allo studio e alla determinazione degli atteggiamenti ideologici che caratterizzano parte della letteratura dell'epoca. 